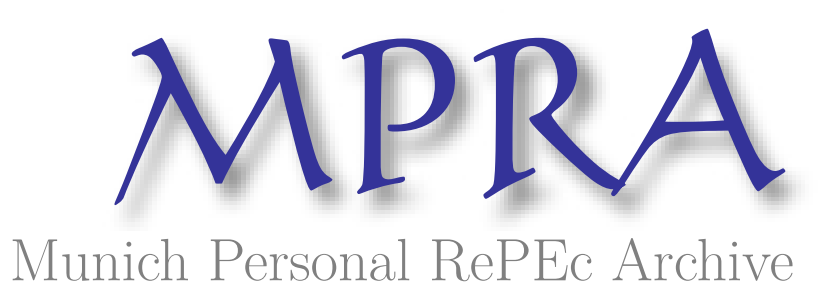

\title{
Multidimensional Poverty Measurement in Tunisia: Distribution of Deprivations across Regions
}

Nasri, Khaled and Belhadj, Besma

2017

Online at https://mpra.ub.uni-muenchen.de/83318/

MPRA Paper No. 83318, posted 22 Dec 2017 04:40 UTC 


\title{
Multidimensional Poverty Measurement in Tunisia: \\ Distribution of Deprivations across Regions
}

\author{
KHALED NASRI \\ FSEGT, University of Tunis EL Manar \\ kholina86@yahoo.fr \\ BESMA BELHADJ \\ FSEGT, University of Tunis EL Manar \\ besma.kaabi@isg.rnu.tn
}

\begin{abstract}
In this paper, we analyze multidimensional poverty in the different regions of Tunisia. The counting approach is used to identify households that are multidimensionally poor and to calculate poverty rates in different geographic areas in Tunisia. In this research, special emphasis is placed on the subgroup decomposability property and the dimensional breakdown. This approach helps us to understand the contribution of each region to the national poverty level and to assess the extent to which dimensional deprivation contributes to poverty measures. The results show that disentangling the sources of household deprivation in each region of Tunisia and calculating the dimensional breakdown by region provides a comprehensive picture of multidimensional poverty in Tunisia and will help decision makers to implement an effective targeting policy.
\end{abstract}

Keywords: Multidimensional Poverty, Counting Approach, the Dual-Cutoff Method, Decomposability, Dimensional Breakdown.

JEL Classification : D12, D31, D63, R11 


\section{Introduction}

The concept of poverty is common; nearly everyone understands it or believesthey understand it. However, the specific meaning we attach to the word depends upon the underlying concept of poverty that we have in mind (Macpherson and Silburn, 1997). In this regard, economists have tried to define poverty in a manner that achieveda public consensus, at least during the period in which they lived.

At the end of the 19th century, Charles Booth $(1894,1903)$ and Robert Hunter (1904) identified the poor populations in London and York based on monetary and sociological indicators, such as the nature and regularity of employment. Rowntree (1901) defined families in York as beingin primary poverty if their total earnings were insufficient to obtain the minimum necessary to maintain a purely physical efficiency. He also noted another aspect of poverty, secondary poverty, by studying the influence of habits and behavior patterns on the composition of family consumption. Rowntree (1901) proved that the relationship between resources and poverty is both variable and profoundly dependent on the specific characteristics of the person in question; it also depends of the environment—natural, geographical and social—in whichthe person lives.

Since 1971, Rawls has supplemented the income indicator by adding a range of "primary social goods" to assess the distribution issue in his theory of justice. These primary social goods are considered by Sen (2009) in the theory of justice as general means that arenot precious in and of themselves. Furthermore, Sen $(1985,1992$, and 2009) argues that poverty should be seen as capability deprivation that involves multiple features of our lives and other concerns. In this spirit, Kaztman (1989) found that 13\% of households in Montevideo, Uruguay, were poor in terms of income but were not deprived of basic needs, whereas $7.5 \%$ of households were in the opposite situation. Ruggeri Laderchi (1997) concluded based on Chilean data that 'income in itself is not...conveying all of the information of interest if the aim is to provide a comprehensive picture of poverty'. Stewart et al. (2007) found that $53 \%$ of the malnourished Indian children in their study did not live in income-poor households and that $53 \%$ of the children living in income-poor households were not malnourished.

Academic researchers are currently debating how to incorporate multidimensionality into poverty measures and how to account for the joint distribution of deprivation across the entire population of a country.

The Report by the Commission on the Measurement of Economic Performance and Social Progress (2009) highlighted the relevance of an approach that considered how developments in one domain of quality of life affected other domains and how developments in various fields are related to income.

In Tunisia, the official poverty estimation is based on the aggregation of household consumption expenditures in a single monetary component.Two poverty thresholds have been established to distinguish poor people and people living in extreme poverty.However, the Tunisian system of social direct transfers is based on the deprivation concept, which is closer to the idea of multidimensional poverty. In fact, the inconsistency between the measurement of poverty and the policy against it may limit the effectiveness of the implemented targeting program.

In this research, we propose a multidimensional measure of poverty based on the deprivations experienced by poor households in multiple dimensions. The Alkire-Foster counting approach (Alkire and Foster, 2011) is used to identify households that are multidimensionally poor and to calculate the poverty rates in different geographic areas in Tunisia. We will also estimate the relative contribution of each region of Tunisia to the overall poverty rate and we will break down the poverty levels by dimension. This will help us to identify the causes and intensity of poverty for each area and will assist the decision makers in targeting poor households.

The rest of the paper is structured as follows. Section 2 presents the multidimensional poverty measurement (essentially, the Alkire-Foster approach), the selection of dimensions and the thresholds of household deprivation. Section 3 applies the methodology to the 2010 Tunisian Household Survey. In this section, we will calculate poverty rates for each area and explore the sources of deprivation for households in the Tunisian regions. Insection 4, we offerrecommendations for public policy. We will conclude this research in section 5 .

\section{Multidimensional Poverty Measurement}

In recent years, poverty and the search for sources of deprivation for people in a particular country and/or between regions have become two recurring themes of economic theory and policy. Analysts, academics and 
development practitioners have always considered the fight against poverty to be one of the ultimate goals of economic development. Moreover, the definition and measurement of poverty appear to be prerequisites for any analysis of this problem. Oneconception of poverty is based on the opportunity deficit, which is the core of the capability approach. Robeyns (2006) addressed how this approach has been put into practice by showing that the capability approach requires the use of empirical research techniques. Shealso noted that given the wide scope of capability applications and the highly multi- and interdisciplinary character of this literature, a wide variety of methods have been used. Recently, a large body of literature on the indicators of poverty and well-being has proliferated. Although all of these indicators signal an important step in the recognition of poverty as a multidimensional phenomenon, they are often based on very different methodologies.

According to Alkire et al. (2015), the main measurement methods that have been explored thus far are the dashboard approach, composite index, Venn diagrams, dominance approach, fuzzy sets and statistical approaches.

These methods can be grouped into two broad categories. One category encompasses the dashboard and composite index approaches, which are implemented using aggregate data from different sources. Dashboards have the advantages of broadening the set of considered dimensions, offering a rich amount of information, and potentially allowing the use of the best data source for each particular indicator and for assessing the impact of specific policies (such as nutritional or educational interventions). However, dashboards also have significant disadvantages. First, dashboards do not reflect the joint distribution of deprivations across the population; for this reason, they are marginal methods (Alkire et al. 2015). Specifically, the dashboard method does not indicate the direction and extent of changes in overall poverty. Composite indices have 'the powerful attraction of a single headline figure' (Stiglitz et al. 2009); however, similar to the dashboard approach, theyare missing a key aspect of multidimensional poverty assessment: the joint distribution of deprivations.

The second category encompasses methods that reflect the joint distribution of deprivations and thus are implemented using data that include information on each dimension for each unit of analysis. Within this second group of methods, Venn diagrams graphically represent the joint distribution of individual deprivations in multiple dimensions. In empirical work, the Venn diagram has been used as an exploratory tool for understandingoverlapping deprivations in various dimensions (Naga and Bolzanis 2006; Atkinson et al. 2010; and Ferreira and Lango 2013). However, Venn diagrams become difficult to read when more than four dimensions are used anddo not per se define the poor. The dominance approach enables us to state whether a country or region is or is not unambiguously less poor than another country or region with respect to various parameters and functional forms. This approach has been extended to the multidimensional context by Declos et al. (2006) and Bourguignan and Chakravarty (2009). However, the dominance approach becomes empirically difficult to implement beyond two dimensions. In addition, like Venn diagrams, the dominance approach does not offer a summary measure.

Regarding measures based on statistical approaches, analysts can construct empirical poverty indices that reflect the joint distribution of deprivations.These indices are widely used in the design of both poverty andwell-being measures (Saisana et al; 2005, Nardo et al; 2008, and Filmer and Pritchett; 1999, 2001). Despite their strengths, statistical approaches have certain limitations in the construction of poverty measures. The axiomatic properties satisfied and not satisfied by these measures remain unclear. In practice, an understanding of these proprieties is important for followingthe behavior of a poverty index given various changes in the joint distribution of deprivations. In the same way, fuzzy set measures, which use relative membership functions,are not decomposable across population subgroups (Cerioli and Zani; 1990). The fuzzy set approach isone of the most attractive methods because it allows the coordination of local and national poverty alleviation policies; this approach will be addressed in detail in section 2.2 in the context of the axiomatic approach.

Two identification measures have been used in the axiomatic approach literature: the aggregate achievement approach and the censored achievement approach. The aggregate achievement approach constitutes the application ofan aggregation function to achievements across dimensions for each person to obtain an overall or aggregate achievement value.A person is identified as poor when her aggregate achievement level is below the aggregate poverty line. This approach resembles the unidimensional case. However, we use the censored achievement approach in our work. A prominent method used in the censored achievement approach is the counting approach, which entails the definition of a deprivation cutoff for each dimension, so that each person is defined as deprived (or not) in each dimension based on a comparison of her dimensional achievement with the 
corresponding deprivation cutoff. The main difference between these two identification approaches is that the counting approach assigns independent importance to each deprivation.

In effect, most multidimensional poverty measures using the axiomatic approach apply a counting technique to identify the poor. Among these methods, we present the Alkire-Foster (AF) methodology based on the dualcutoff method in the following section. The resulting measures have a number of convenient features. First, they include the two necessary steps of poverty measurement, namely, identifying the poor and aggregating the information into a single headline figure. Second, unlike dashboards and composite indices, the resulting measures can use the joint distribution of achievements in both the identification and aggregation steps. Third, AF measures satisfy population subgroup decomposability and the dimensional breakdown property.

\subsection{The Alkire- Foster Approach}

Before delving deeply into the steps of the AF methodology, it is worth recalling that in the unidimensional case, a person is poor if she is deprived. However, in the multidimensional context, the identification of the poor is more complex; the terms 'deprived' and 'poor' are no longer synonymous. A person who is deprived in any particular dimension may not necessarily be considered poor. Rather, an identification method with an associated identification function is used to define who is poor. In the literature, determining the weights of each dimension is always an arbitrary choice because there are no universal guidelines for their establishment. The approach commonly used to assign weights in multidimensional indices of well-being has been equal weighting. Here, we propose giving the same weight to each dimension selected.

Consider a nation or any geographic region with (n) households and (d) dimensions. Let $Y=\left|y_{i j}\right|$ represents an achievement matrix of a society, where $\left(y_{i j}\right)$ is the achievement of the $i^{\text {th }}$ household in the $j^{\text {th }}$ dimension for all $j=1, \ldots, d$ and all $i=1, \ldots, n$. The row vector $\left(y_{i .}\right)=\left(y_{i 1}, y_{i 2}, \ldots ., y_{i d}\right)$ summarize the achievements of household in the (d) dimensions, whereas, the column vector $\left(y_{. j}\right)=\left(y_{1 j}, y_{2 j}, \ldots ., y_{n j}\right)$ represents the distribution of achievements in the $j^{\text {th }}$ dimension across the (n) households. The deprivation cut-off for the $j^{\text {th }}$ dimension is indicated by $\left(z_{j}\right)$.Corresponding to any matrix $Y=\left|y_{i j}\right|$, a $(n \times d)$ dimensional deprivation matrix $g^{0}=\left|\left(g_{i j}^{0}\right)\right|$ is constructed. Each element of $g^{0}$ is equal to one when the $i^{\text {th }}$ household is deprived in the $j^{\text {th }}$ dimension and is equal to zero when the household is not deprived. In other words, each entry of the matrix $g^{0}$ can take only two values as follows:

$g_{(i j)}^{0}=\left\{\begin{array}{l}1 \text { if } y_{i j}<z_{j} \\ 0 \text { if } y_{i j} \geq z_{j}\end{array}\right.$

Based on matrix $g^{0}$, we construct an n-dimensional column vector $c=\left|c_{i}\right|$ where each element $c_{i}$ indicates the number of deprivations suffered by the $i^{\text {th }}$ household. Then, it is a matter of deciding on how many dimensions household should be deprived so as to be considered multi-dimensionally poor. That is equivalent to setting a second poverty line $(k)$. A household is considered multi-dimensionally poor if $c_{i} \geq k$. The decision on the value of $k$ is left to researcher and several different values can be tested. One could set $k=1$, requiring an individual to be deprived in at least on dimension to be considered multi-dimensionally poor and this would correspond to the union approach, Chakarvarty and Bourguignon (2003). This approach is commonly used, but as the number of dimensions increases, it can lead to exaggerated estimates of poverty. Other would set $k=d$, requiring an individual to be deprived in all considered dimensions so as to be multi-dimensionally poor; the intersection approach is considered too restrictive. Clearly, other intermediate values for $k$ may be more appropriate. According to the above criterion, once the poor households has been identified. A logical next step 
is to suppress the data of the non poor to focus on the poor. To do that, a censored matrix $g_{i j}^{0}(k)$ is defined from $g^{0}$ by $g_{i j}^{0}(k)=0$ if $c_{i}<k$ while $g_{i j}^{0}(k)=g_{i j}^{0}$ if $c_{i} \geq k$ this new matrix provides a picture of all the deprivations that are experienced by the poor. We can also define a censored deprivation vector $c(k)$. It takes as a value the number of deprivation if the household is poor and 0 otherwise.

Based on this identification method, Alkire and Foster (2011) define the following poverty measures. The first natural measure is the proportion of households that are multi-dimensionally poor. This headcount ratio is obtained by dividing the number of individuals in the poor set $(q)$ by the total number of households $(n)$. It is noted by $H=\frac{q}{n}$. However, this measure is insensitive to the intensity and distribution of poverty. It also fails to satisfy the properties of transfer and monotonicity in the single dimensional context Sen (1976). In the multidimensional context, $H$ violates dimensional monotonicity: If a household already identified as poor becomes deprived in an additional dimension in which the household was not previously deprived, $H$ does not change. In the other hand, this measure is not flexible to dimensional decomposition, which is often useful for policy recommendation. To overcome the limitations of the multidimensional headcount ratio, Alkire and Foster propose the Adjusted Headcount Ratio $M^{0}$, defined as follow:

$M^{0}=\mu\left(g_{i j}^{0}(k)\right)=H \times A$

Where $A=\frac{\left|g_{i j}^{0}(k)\right|}{q . d}$, is the average deprivation share across the poor and $\left|g_{i j}^{0}(k)\right|$ denote summation of elements of the censored vector of deprivation counts $c(k)$. This adjusted headcount ratio summarizes information on both the incidence of poverty and the average extent of a multidimensional poor household's deprivation. It satisfies the property of dimensional monotonicity and the subgroup properties. But, if any of multi-dimensionally poor became more deprived in one dimension, $M^{0}$ would not change. It violates the monotonicity. For this reason, it is important to consider a FGT class of A-F multidimensional poverty measures:

$M^{\alpha}=\mu\left(g_{i j}^{\alpha}(k)\right)$. For $\alpha>0$

In particular, the adjusted poverty gap is given by:

$M^{1}=\mu\left(g_{i j}^{1}(k)\right)$

Where the matrix $g^{1}(k)$ is obtained from $g_{i j}^{0}(k)$ matrix defined above. Recall that each gap is given as follows:

$g_{i j}^{1}(k)= \begin{cases}\left(z_{j}-y_{i j}\right) / z_{j} & \text { if } c_{i} \geq k \\ 0 & \text { otherwise }\end{cases}$

In other words, $g_{i j}^{1}(k)=\operatorname{Max}\left(\left(z_{j}-y_{i j}\right) / z_{j} ; 0\right) . M^{1}$ can be interpreted as the average deprivation gap that the poor experience from the total potential deprivation that the society could experience. It can be expressed as the product between the headcount ratio $H$, the intensity of poverty $A$, and the average deprivation gap $\mathrm{G}$, where $G=\frac{\left|g_{i j}^{1}(k)\right|}{\left|g_{i j}^{0}(k)\right|}$. This adjusted poverty gap satisfies not only dimensional monotonicity, but also 
monotonicity: if an individual becomes more deprived in any dimension in which they are already deprived, M1 will increase. Similarly, the adjusted poverty severity is given by:

$$
M^{2}=\mu\left(g^{2}(k)\right)=H \cdot A \cdot S
$$

Where $S=\left|g^{2}(k)\right| /\left|g^{0}(k)\right|$ or the average poverty severity in all dimension in which poor individuals are deprived. This measure is sensitive to the inequality in the distribution of deprivation among the poor. Generally, each poverty measure embodies some normative principles. These normative judgments are reflected in its mathematical properties. In multidimensional context, Alkire and Foster (2011a) classified the properties into four categories: the invariance properties, the dominance properties, the subgroup properties and the technical dominance properties. In this work, a special emphasis is placed on the subgroup decomposability and the dimensional breakdown.

\subsection{Choosing Dimensions}

When measuring multidimensional poverty, several choices must be made, some of which are the same as those made in the unidimensional case (e.g., choice of unit of analysis) and some that are specific to the multidimensional case. One of the first decisions regards the selection of dimensions. Alkire (2008) noted that most researchers have implicitly settled on one or more of five selection methods, which are the following: data availability; normative assumptions; public consensus; participatory process; and the selection ofdimensions based on empirical claims about what people appear to value according to surveys and people's behavior. In this regard, de Kruijt and Rutten (2007) use a Maldivian household survey in which respondents are asked to rank dimensions according to their relative importance in determining the overall standard of living. Clearly, the choice of dimensions for a multidimensional poverty index must be sensitive to the context of the evaluation and in particular to the characteristics of the countries for which theindex is primarily intended. Anand and Sen (1997) observe that issues of poverty in developing countries involve such crucial matters as hunger, illiteracy and the lack of health servicesandsafe water. However, these deprivations may not be common in more developed countries, where hunger is rare, literacy is close to universal and health services are typically widespread.Robeyns (2006) strongly advocates that however the dimensions are selected, the reports of researchers, analysts and government officials should includeexplicitdescriptions ofthe process used to select those dimensionsas a means offostering public debate and feedback. She suggests that the write-ups should clearly explain why the selected dimensions or indicators are deemed to be things people value and have reason to value. Authors should justify the methodology by which the dimensions were selected and should articulate the dimensions that were considered important but omitted due to feasibilityconsiderations, such as missing data. In this paper, dimensions that are important in society and that provide suitable guidance for public policy are selected.

\subsection{Deprivation Thresholds}

Once the dimensions have been selected, the poverty lines must be established. A desirable method is to set a poverty line for each dimension. In a multidimensional context, absolute lines are typically used. These poverty lines reflect a value judgment about poverty but are often based on a local or national consensus. Whatever the means used to determine the poverty lines, it is important to explicitly describe the process through which thevalues were decided. In this paper, the poverty line is defined as the individual monetary requirements that ensure a minimum level of well-being for a household. It is affected by changes in household characteristics such as size, demographic composition and place of residence. However, several problems arise in the calculation of this threshold, including the problems of reference and identification (Pollak and Wales 1979 and Pollak 1991). Indeed, it is not easy to overcome the problem related to the definition of income in developing countries, particularly in rural and non-municipal areas. Approaches used to determinethis threshold in developing countries such as Tunisia often focus on the cost of basic needs (CBN) and the nutritional energy method (EFI). The CBN method determines the absolute poverty line based on estimates of both food and non- 
food components. The food poverty line is defined based on nutritional needs that satisfy a particularcalorie requirement. The estimation of a non-food poverty line is intended to account for the consumption of non-food goods and services, such as health, clothing, education, housing, etc.

\section{Empirical Illustration using Tunisian Data}

\subsection{Data, dimensions and deprivation thresholds}

The data we use are taken from the 2010 Tunisian national consumption survey conducted by the INS (National Statistics Institute of Tunisia).This survey covers the entire country (large cities, small and medium towns and rural areas) and encompasses three areas of study: i) the expenses and acquisitions of households, ii) the food consumption and nutritional status of households, and iii) household access to community services (i.e., health and education).This survey is a primary source of information on the nutritional situation of the Tunisian population and on their access to public services such as health care, education and transport at the regional level. The sampling frame is stratified in two geographic criteria: the governorate and the living environment. The strata used are the following: large corresponding municipalities with over 100,000 citizens, neighboring towns of small and medium municipalities, and a layer of outlying communities. The 2010 Tunisian national consumption survey covered a sample of 13392 households theoretically drawn in a random survey. The survey covers the entire year, allowing INS to assess the level of consumption and welfare of Tunisian people based on their geographic, demographic and socioeconomic characteristics. Difficulties in procuring basic resources, such as education, health, etc., in different areas of Tunisia are converted intohousehold expensesand the downstream generation of difficult living conditions. For example, the absence of health services or schools in rural areas implies additional fees for transport, which aggravates the situation of a poor household. The links between dimensions motivate our empirical analysis space. We use household spending in order to analyze regional multidimensional poverty. This approach is generally preferred because expenses seem much more closely related to quality of life (Slesnick 1998 and Deaton 1997).First, we exclude dimensionsthat do not reflect hardships on households (Belhadj 2012). Thus, dimensions that are notmajor sources of deprivation and are very hard to eliminate in developing countries should be excluded. These dimensions include leisure and culture; alcoholic beverages and tobacco; furniture and art; and telecommunication. The analysis of deprivationsbased on a comprehensive study of dimensions that contribute more to the welfare of households nationwiderequires the exclusion of dimensions that do not have magnitudes in non-municipal areas. We retain three dimensions (food, health and education) that are related to social public policies in Tunisia. In fact, there are two types of instruments for social transfer in Tunisia, one of which is the Tunisian Universal Food Subsidies Program. Since 1970, basic foodstuffs have been subsidized to protect the purchasing power and nutritional status of the poor. There is also the National Program of Assistance to Needy Families, whichinvolves the allocation of monthly financial assistance based on the number of children enrolled in school and the allocation of free health care cards (for which the eligible population is defined according to the national poverty line and regional quotas) or reduced-price health care cards (for which the eligible population is defined based on the minimum wage).In addition, Tunisiaallocated close to $6.3 \%$ of its national wealth to health spending in 2010 . Thus, the share of overall health expenditure covered by social security has increased from $32.2 \%$ in 2000 to $47.7 \%$ in 2010 (OASIS ${ }^{1}$ 2014).

Therefore, we estimate poverty thresholds for each variant in our analysis; each threshold indicates a level of food or non-food consumption below which a person is considered poor. These thresholds take into account the consumption patterns of Tunisians and the cost of living in different regions of Tunisia. In Table (1), we present the strata of Tunisians and the poverty line corresponding to each dimension $\mathrm{j}$.

The INS calculates the food poverty line $\left(Z_{s}^{A}\right)$ by multiplying the median cost $\mathrm{k}$ cal of reference group $(C s)$ by the recommended energy needs $(B E R s)$ at each stratum $s: Z_{s}^{A}=C_{s} \times B E R_{s} \times 365$ days .

The non-food thresholds include a threshold for judging whether an individual is deprived in the health dimension and a threshold to assess their situation in the educational dimension. The selection of average spending in thesetwo dimensions (health and education) as thresholds of poverty is justified by the idea that utility is related not only to absolute consumption or wealth but also to an individual's relative position along

\footnotetext{
${ }^{1}$ Organization Assessment for Improving and Strengthening Health Financing.
} 
these dimensions within a given reference group, as demonstrated by Kuziemko and Norton (2014), whoformulated the last-place aversion model to show that the economic benefit and well-being of a household are not determined simply by the desire to accumulate wealth but also by the household's relative position vis-àvis others who live in the same area. According to this model, the thresholds of the two dimensions (health and education) vary across the geographical areas of Tunisia. To complete the dual-cutoff method, we advocate a line of $K=2$, from which we consider a household multidimensionally poor.

\subsection{Multidimensional Measurement of Poverty}

In the multidimensional measurement setting, where there are multiple variables, identification is substantially more challenging. In Table (2), the number of poor people in the various dimensions depends on the selected poverty cut-off level. We can see that if the union definition (being deprived in at least one dimension) is adopted, then $91.4 \%$ of Tunisian households are poor. It was observed that an increase in the number of dimensions augmented poverty and led to exaggerated results. In contrast, the intersection method yields more restricted results by requiring that a household be deprived in at least three dimensions to be considered multidimensionally poor. The intersection approach leads to a poverty rate of nearly $15 \%$, which coincides with the official poverty rate calculated by the INS in 2010. If the poverty cut-off level is two dimensions (i.e., people are deprivedin at leasttwo dimensions), $57.7 \%$ of the population are members of poor households. The following Venn diagram shows the differencesamong these three approaches to the identification step.

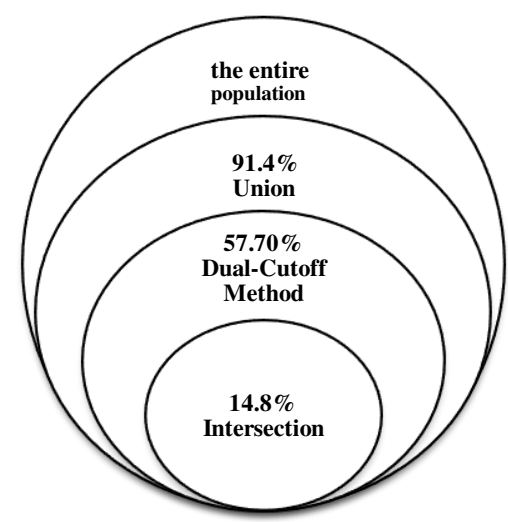

In counting identification methods, the criterion for identifying the poor can range from 'union' to 'intersection'. The union criterion identifies a person as poor if the person is deprived in any dimension andindicates the swath of society that risks poverty at some point in time. In other words, if the intention is to design measures to prevent poverty in the future, vulnerability to poverty must be measured and the union approach is helpful. In contrast, the intersection criterion identifies a person as poor only if she is deprived in all considered dimensions. According to the AF methodology, the number estimated can be interpreted as extreme poverty.Between these two criteria is thedual-cutoff method.

To avoid criticisms of the multidimensional headcount ratio (e.g., it does not take into account the breadth of multidimensional poverty, it does not satisfy dimensional monotonicity, and it is not decomposable) the adjusted headcount ratio $\left(M^{0}\right)$ has been used instead of a multidimensional headcount. Specifically, we use the cut-off of two dimensions. The third column of table 3 reports the adjusted headcount poverty rate for the different cutoffs. If $K=2$, then $M^{0}$ is 0.434 because $M^{0}=H . A$. Because $\mathrm{H}$ is equal to 0.577 and A is equal to $\frac{M^{0}}{H}=$ 0.752. A can be interpreted as the poor being deprived in $75.2 \%$ of all dimensions. If a poor household becomes more deprived in one dimension, the $M^{0}$ measure does not change because it violates monotonicity. However, the $M^{1}$ measure increases. We can see that $M^{1}=0.268$. In addition to $\mathrm{H}$ and $\mathrm{A}, M^{1}$ consider the average poverty gap $\mathrm{G}$, which is equal to $\frac{M^{1}}{H . A}=0.61$. In the next section, we show that these measures differ across 
Tunisianregions and use the decomposition property of poverty measures across groupsto provide a complete view of multidimensional poverty in Tunisia and to estimate the relative contribution of each region to the overall poverty measure.

\subsection{Distribution of Deprivations among Regions}

The application of the AF methodology in each region of Tunisia shows that poverty measures vary considerably among the seven regions of Tunisia. According to Table (3), we can conclude that the western regions are the poorest Tunisian regions. Specifically, the incidence, depth and severity of poverty exceed 50\%, 30\% and 20\%, respectively, in the Northwest and Central West. Great Tunis is the least poor region based on all poverty measures. The Central East has the second lowest poverty rate. The Northeast has the third lowest poverty rate, followed by theSoutheast.

Based on Table (3), we can see that the contribution of Great Tunis to the overall adjusted headcount ratio is $0.162 \times \frac{0.321}{0.439}=0.118$, or $11.8 \%$. The contributions of the Central West, Southwest and Northwest tooverall $M^{0}$ are $21.5 \%, 11.9 \%$ and $15.4 \%$, respectively. It is clear that we have four Tunisians regions whose contributions exceed their population shares, which suggests that there is a seriously unequal distribution of poverty in Tunisia.

Figure (1) shows the contribution of each region to the overall poverty measure $M^{0}$. Note that the contribution of each region to overall poverty depends both on the level of poverty in the region and on the share of the population represented by the region. Obviously, the sum of the contributions of all regions must be $100 \%$.

The measure of poverty differs significantly across Tunisian habitats, which shows the influence of region on household deprivations. To refine our work, we analyze the distribution of Tunisian deprivations in different strata and in urban and rural areas in each region.

\subsection{Distribution of Deprivations within Regions}

We find that people living in rural areas of Tunisia are the poorest. The poverty rates in rural areas exceed the national poverty rate in all regions of Tunisia. For example, the poverty rate in Great Tunis is $57 \%$; in the Central East and Southeast, the rate exceeds 50\%. For the Northwest and Southwest regions, estimated poverty in the two strata resembles that estimated for urban and rural areas. Although these poverty measuresarelower than the estimated national rate in urban areas, they vary from one stratum to another and from one region to another. From the results in Table (4), we can conclude that people living in large cities in the Central East, Central West and Southeast regionsare less poor, with poverty rates of $19 \%, 35 \%$ and $29.3 \%$, respectively, compared with people who live in large cities in the other regions. To enhance understanding of the composition of poverty in Tunisia, we present the decomposition of poverty measure across the different dimensions within these regions. This process will help us to identify causes and the intensity of poverty in each area.

\subsection{Dimensional breakdown}

All Alkire-Foster measures can be unpacked to reveal the dimensional deprivations thatcontribute the most to poverty for any given group. Recall that this key property is not available with the standard headcount ratio. The factor contributions to poverty were calculated by aggregating the share of the respective population that is both poor and deprived in a particular dimension and dividing that share by the total number of dimensions. From the results shown in Table (5), we conclude that the contributions from health and education are quite high, contributing $43.48 \%$ and $41.95 \%$, respectively, to the national poverty rate in 2010 , whereas the food dimension contributes 14.57 percent to the overall poverty rate. These contributions vary from one geographic area to another.Table (6) uses the methodology outlined earlier to identify the dimension-specific changes driving the variation in regional poverty measure $M^{0}$. 
The final column of Table (6) reproduces the regional poverty levels found in column 4 of Table (3), and the rows decomposethese poverty measures by dimension. The first row gives the decomposition for the Great Tunis population, with column 2 indicating that 43 percent of households in Great Tunis are both multidimensionally poor and deprived in the health dimension. Similarly, we can see that over $70 \%$ of households are multidimensionally poor and suffering in the health dimension in the Central West. Moreover, 66.6 percent of poor households in the Northwest are deprived in the health dimension. Among the poor in the Southwest, $60 \%$ are affected by health deprivation. Column 5 has the overall M0 for Great Tunis, which is simply the average of the first row. The second row expresses the same data in percentage terms, with column2 providing the relative contribution of the health dimension to the Great Tunis level of $M^{0}$.

From the results in Table (6), we can see that the health dimension is the main source of Tunisian deprivation. Health contributes $45.96 \%, 45.44 \%$ and $44.28 \%$ to poverty in Great Tunis, the Northeast and the Southwest, respectively. These values are greater than the relative contribution of health to the national poverty rate (43.48\%). In contrast, the contribution ofthe health dimension in the Central West is lower than the relative contribution of health to the national level of M0. According to column3, the education dimension contributes more to poverty in the Northeast $(45,06 \%)$ than in the Central West $(39,41 \%)$. However, 70 percent of poor households in the Central West are affected by education deprivation. In addition, 61, 7\% of Northwest households are deprived not only in the education dimension but also in at least one other dimension.Column4shows the relative contributions of the food dimension to the various measures of regional poverty. The contribution of the food dimension goes from $9.52 \%$ and $14.28 \%$ in Great Tunis and the Southwest, respectively, to over $17 \%$ in the Northwest and Central West. This dimensional breakdown shows that certain Tunisian areas represent a priority in the food dimension, specifically,those areas for which the relative contribution at the regional level exceeds the contribution of the food dimension to overall poverty. The public authority must target the food dimension in each priority area with direct transfers, which seemto be an effective means of fighting deprivation in this vital dimension.

\section{Prospects and Recommendations for Public Policy}

This research enabled the generation of apoverty profile for each area of Tunisia. The calculated dimensional breakdown provides a comprehensive picture of the distribution of deprivations across regions. This breakdown will help decision makers to target the poorest households and to determine the budgetary share to be allocated to each area to fight dimensional deprivation. The findings show that the poverty rates in rural areas exceed the national poverty rate. Therefore, if policy makers seek to improve the living standards of poor households, they must intensify their efforts in rural areas, especially with respect to dimensions that contribute the most to household poverty. In this regard, the government must implement a targeted regional program designed to alleviate the main sources of poverty in the different regions through public investment (e.g., budgetary grants, targeted loans, and integrated rural development projects). The western regions of Tunisia are polydisadvantaged regions and require special attention, especially in the food and health dimensions. To address deprivations in the health dimension, the public authority should take action to strengthen its role in this area by improving the medical workforce in regional and rural areas, which should be accomplished by encouraging specialist doctors to work in these regions and by providing professional medical equipment.

In contrast, Ravallion (2011) argues that it is better to target the income poor to reduce income poverty and that, analogously, it is better to target the specific people that are deprived of public services to reduce deprivation in such services. In this context, policymakers can use the multidimensional headcount ratio $\mathrm{H}$ as the proportion of beneficiary households and use M0 as the proportion adjusted by A (i.e., the average proportion of deprivation experienced by the beneficiaries). Two attributes are recommended for such a targeting program. First, if a household becomes deprived in one additional dimension, it should be included in the group considered poor. For targeting purposes, this practice would mean that an increase in the number of deprivations directly increases a household's chances to become eligible for the program. Moreover, if a poor household's performance improves in a non-deprived dimension, this improvementshould not affect its identification as poor. In other words, high performance in one dimension cannot compensate for deprivation in other dimensions. For targeting purposes, this protocol means that eligibility is not affected by performance in dimensions that are not relevant to 
the program. The incorporation of these properties into a targeting program has clear advantages over the traditional one-dimensional (proxy-means test) programs, which implicitly allow substitution between dimensions. Second, to improve the impact of social transfers on households' welfare, policy makers can use M2, which prioritizes the poorest of poor households.

Targeting the source of the deprivation of Tunisian households will reduce the inclusion error and therefore reduce the waste of public resources. However, the exclusion error will be significant because households that are deprived only in one dimension are excluded from the group considered poor.

Another important implication arising from this research is the identification of households likely to be poor in the future. Vulnerable households comprise households that are deprived in only one dimension, which — based on the methodology described above-are excluded fromthe group of households considered poor. This implication underscores the importance of well-targeted povertyprevention policies in addition to policies aimed at reducing existing poverty. There is an urgent need for the introduction of social protection policies to protect households from becoming poor in the future.

\section{Conclusion}

The generation of a comprehensive picture of poverty in Tunisia requires a multidimensional approach to understand the sources of deprivations in different regions.In this paper, poverty is defined as deprivations in certain basic needs, including food and non-food needs (Haughtan and Khandker 2009). Non-food needs include health and education, and difficulties in procuring these basic resources in different areas of Tunisia are converted into downstream household expenses, which generate difficult living conditions. The measurement of poverty is based on household spending, which seems much more closely related to quality-of-life level.The empirical illustration using 2010 Tunisian data allows us to derive results that indicate the main sources of deprivation of households in different geographical areas. The poverty rate in Tunisia varies by region; there are also variations within each region (for example,urban areas are characterized by low poverty rates), which makes intra-regional analysiscritical to targeting the population, area and prioritized dimension. We conclude that the western regions of Tunisia are poly-disadvantaged and require special attention, especially in the food and health dimensions.To addresshealth-related deprivations, the public authority should take action to strengthen its role in this dimension. Disentangling the sources of deprivation of households in each region of Tunisia and the calculated dimensional breakdown by regionwill help decision makers to targetthe poorest households and to determinethe budgetary share to be allocated to each area in order to fight dimensional deprivation.

\section{References}

Alkire S, Foster J. E, Seth S, Santos M. E, Roche J. M, and Ballon P. 2015. Multidimensional Poverty Measurement and Analysis, Oxford: Oxford University Press

Alkire S, Foster J .2011. Counting and multidimensional poverty measurement. Journal of Public Economics 95 (7): 476-487.

Alkire S, Santos M E .2010. Acute multidimensional poverty: A New index for developing countries? OPHI Working Paper Series no 38. Oxford University.

Alkire S.2007. Choosing Dimension: The capability approach and multidimensional poverty. In : Kakwani N, Silber J (ed) the Many Dimensions of Poverty, PALGRAVE MACMILLAN, New York pp 89-119.

Ali Abdel Gadir A, Shenggen F.2007. Public Policy and Poverty Reduction. In: the Arab Region, The Arab Planning Institute, Kuwait.

Anand S, Sen A K .1997. Concepts of human development and poverty: a multidimensional perspective, Human Development Papers, United Nations Development Programme, New York.

Atkinson A B, Marlier E, Monatigne F, and Reinstadler A .2010. Income Poverty and Income Inequality, in Atkinson and Marlier (eds.), Income and Living Conditions in Europe. Eurostat Statistical Books. Luxembourg: Publications Office of the European Union, 101-32.

Ayadi M, Chtioui N, El Lahga A .2005. Analyse Multidimentionnelle de la Pauvreté en Tunisie entre 1988 et 2001 par une Approche non-Monétaire, paper presented to the 4th PEP Research Network General Meeting, June 13-17, Columbo, Sri Lanka.

Bourguignon F, Chakravarty S .2003. The measurement of multidimensional poverty, Journal of Economics Inequality, 1(1), 25-49. 
Bourguignon, F, Chakravarty, S. R. (2009). 'Multidimensional Poverty Orderings: Theory and Applications', in K. Basu and R. Kanbur (eds), Arguments for a Better World: Essays in Honor of Amartya Sen, i: Ethics, Welfare, andMeasurement. Oxford: Oxford University Press, ch. 18.

Booth, C. (1894). The Aged Poor: Condition. London: Macmillan.

Booth, C. (1903). Life and Labour of the People in London. London: Macmillan.

Betti G, Cheli B, Lemmi A, Pannuzi N .2005. Estimating the Dynamics of Poverty in Europe via TFR Approach: the Experience of the Second Half of the Nineties, the 1st meeting of the Society for Study of Economic Inequality, Palma de Mallorca, Spain, July 20-22.

Belhadj B .2011. Pauvreté persistante, chronique et transitoire Nouvelle méthode axiomatique, Éthique et économique, 9(1).

Belhadj B, Limam M .2012. Unidimensional and Multidimensional Fuzzy Poverty Measures: New Approach, Economic Modelling, 29(4): 995-1002.

Belhadj B .2012. New Weighting Scheme for the Dimensions in Multidimensional Poverty Indices, Economics Letters, 116, 304-307.

Besley T and Kanbur R .1993.The Principles of Targeting", in M. Lipton and J. Van der Gaag (eds.), Including the Poor, The World Bank, pp. 67-90.

Bibi S and El Lahga A 2006. Les mesures multidimensionnelles de la pauvreté: une application sur l'Afrique du Sud et l'Égypte, Centre interuniversitaire sur le risque, les politiques économiques et l'emploi Cahier de recherche/ Working Paper, 06-39.

Chakravarty S, D'Ambrosio C .2006. The Measurement of social exclusion, Review of Income and Wealth, 52, 3, 377-398.

Cerioli A, Zani S .1990. A Fuzzy Approach to the Measurement of Poverty, Income and Wealth Distribution, Inequality and Poverty Studies in Contemporary Economics 1990, pp 272-284.

Dutta I, Pattanaik P K, Xu Y.2003. On Measuring Deprivation and the Standard of Living in a Multidimensional Framework on the Basis of Aggregate Data, Economica, 70, 197-221.

Daniel T, Slesnick .1998. Empirical Approaches to the Measurement of Welfare, Journal of Economic Literature, XXXVI, 2108-2165.

Deaton A .1997. The Analysis of Household Surveys: A Micro Econometric Analysis for Development Policy, The World Bank, The Johns Hopkins University Press, Washington D.C. 133-181.

De Kruijk H and Rutten M .2007.Weighting dimensions of poverty based on people's priorities: Constructing a composite poverty index for the Maldives, Q-Squared Working Paper 35, Centre For International Studies, University of Toronto.

Duclos J-Y, Sahn D, Younger S D .2006a. Robust multidimensional poverty comparisons, The Economic Journal, (116), 514, 943-968.

Ferreira, F.H.G. and Lugo, M.A. 2013. 'Multidimensional PovertyAnalysis: Looking for a Middle Ground', World Bank Research Observer, 28(2): 220-35.

Filmer, D. and Pritchett, L. H. 1999. 'TheEffect ofHouseholdWealth on Educational Attainment: Evidence From 35 Countries', Population and Development Review, 25(1): 85-120.

Filmer, D. and Pritchett, L. H. 2001. 'Estimating Wealth Effects without Expenditure Data-or Tears: An Application to Educational Enrolments in States of India', Demography, 38(1): 115-32.

Foster J, Greer J, Thorbecke E .2010. The Foster-Greer-Thorbecke (FGT) Poverty Measures: Twenty-Five Years Later, Journal of Economics Inequality, 8, 491-524.

Haughton J and Khandker S. R .2009. Handbook on Poverty and Inequality, Washington, DC: World Bank.

Hunter, R. (1904). Poverty. New York: Macmillan.

Kaztman, R. 1989. 'La Heterogeneidad de la Pobreza. El Caso de Montevideo', Revista de la Cepal, 37: 141-52.

Kuziemko I, Buell R, Reich T, Norton M I .2014. Last-Place Aversion: Evidence and Redistributive Implications, the Quarterly Journal of Economics 129 (1), 105-149.

Kanbur SMR .2005. Growth, Inequality and Poverty: Some Hard Questions. Journal of International Affairs, 58(2), 223-232.

Lavallée E, Olivier A, Pasquier-Doumer L, Robillard A-S. 2009.Cibler les politiques de lutte contre la pauvreté dans les pays en développement? Quel bilan des expériences dans les pays en développement? DIAL Working paper DT/2009/03.

Lanjouw P, Ravallion M .1995. Poverty and Household Size. Economic. Journal. 105, 1415-1434.

OASIS .2014. Analysis of the health financing system in Tunisia. Technical report.

Observatoire économique et statistique d’Afrique subsaharienne. Série méthode $\mathrm{n}^{\circ} 7.2009$. Méthodologie d'élaboration de la ligne de pauvreté sur une base harmonisée: Bilan dans les Etats membres d'AFRISTAT.

Macpherson S, Silburn R .1998. The meaning and measurement of poverty. In Dixon J, Macarov D (ed) Poverty: A Persistent Global Reality, ROUTLEDGE, pp 1-19. 
Nardo, M., Saisana, M., Saltelli, A., Tarantola, S., Hoffman, A., and Giovannini, E. 2008. Handbook on Constructing Composite Indicators: Methodology and User Guide (No. 2008/3). Ispra, Italy: OECD Publishing

Naga, R. H. A. and Bolzani, E. 2006. 'Poverty and Permanent Income: A Methodology for Cross-Section Data', Annales d'Economie et de Statistique, 81: 195-223.

Nolan B, Whelan C .2011. Poverty and Deprivation in Europe. Oxford: Oxford University Press.

Pollak R A and WALES T J .1979. Welfare Comparisons and Equivalence Scales, American Economic Review, 69, 216-221.

Pollak R A.1991. Welfare comparisons and situation comparisons, Journal of Econometrics, Elsevier, vol. 50(12), pages 31-48, October.

Ravallion M .2008. Poverty Lines. In Larry Blume and Steven Durlauf (2008). The New Palgrave Dictionary of Economics, 2nd edition, (eds) London: Palgrave Macmillan forthcoming.

Ravallion M .2011. the Two Poverty Enlightenments Historical Insights from Digitized Books Spanning Three Centuries, Policy Research Working Paper, 5549.

Ravallion M, Lokshin M .1998. Subjective Economic Welfare. Policy Research Working Paper, World Bank, Washington D.C.

Ravallion M .2011. On multidimensional indices of poverty? Journal of Economic Inequality, 9 (2): 235-248.

Rawls, J. 1971. A Theory of Justice. Cambridge, MA: Harvard University Press.

Rowntree, B. S. 1901. Poverty: A Study of Town Life. London: Macmillan.

Robeyns I .2006. The Capability Approach in Practice. Journal of Political Philosophy, 14(3): 351-76.

Ruggeri Laderchi C.1997.Poverty and its Many Dimensions: The Role of Income as an Indicator, Oxford Development Studies, 25 (3): 345-60.

Saisana, M., Saltelli, A. \& Tarantola, S. 2005. Uncertainty and sensitivity analysis techniques as tools for the quality assessment of composite indicators. Journal of the Royal Statistical Society: Series A, 168, 307323.

Sen A K .1985. Commodities and Capabilities.Oxford: Elsevier Science Publishers.

Sen A, Anand S .1997. Concepts of Human Development and Poverty: A Multidimensional Perspective. In: Poverty and Human Development: Human Development Papers 1997. New York: United Nations Development Program.pp.1-20.

Sen A K .1992. Inequality Re-examined. Oxford: Clarendon Press.

Sen A K .2009. The Idea of Justice, The Belknap Press of Harvard University Press, Cambridge, Massachusetts.

Silber J .2005. Measuring Multidimensional Poverty: An Empirical Comparison of Various Approaches. Review of Income and Wealth 51(1), 145-174.

Stephen P, Jenkins J M .2007.New Directions in the Analysis of Inequality and Poverty. Discussion Paper Series, Institute for the Study of Labor IZA DP, No. 2814.

Stewart, F., Saith R., and Harriss-White, B. 2007. Defining Poverty in Developing Countries. Basingstoke: Palgrave Macmillan.

Stiglitz, J. E., Sen, A., and Fitoussi, J.-P. 2009. Report by the Commission on the Measurement of Economic Performance and Social Progress, <www.stiglitz-sen-fitoussi.fr>.

Tsui K .2002. Multidimensional poverty indices.Social choice and Welfare 19, 69-93.

Venn, J. 1880.On the Diagrammatic and Mechanical Representation of Propositions and Reasonings. Philosophical Magazine and Journal of Science, Series 5, 10(59): 1-18.

World Bank .2000. World Development Report 2000/2001: Attacking Poverty, oxford University Press.

Zheng B .2001. Statistical Inference for Poverty Measures with Relative Poverty Lines. Journal of Econometrics 101337356. 